\title{
PNO: SERVIÇO WEB PARA CONCESSÃO INTERATIVA E TUTORADA DE PLANOS DE NEGÓCIO
}

\author{
PNO: WEB SERVICE FOR INTERACTIVE AND TUTORED CONCEPTION \\ OF BUSINESS PLANS
}

\section{PNO: SERVICIO WEB PARA LO DISEÑO INTERACTIVO Y TUTORADO DE PLANES DE NEGOCIO}

\begin{abstract}
Vanessa C. Carvalho Nobre, Aluna do Mestrado em Comunicação Multimídia da Universidade de Aveiro-Portugal vanessa.ccnobre@gmail.com

Lídia Oliveira, Professora Auxiliar com agregação da Universidade de Aveiro-Portugal Investigadora no CETAC.MEDIA - Centro de Estudos das Tecnologias e Ciências da

Comunicação lidia@ua.pt
\end{abstract}

\section{Resumo}

O objeto de estudo consiste num serviço web para concessão interativa e tutorada de planos de negócio. A metodologia de investigação-ação-desenvolvimento aplica-se mediante duas fases: exploração preliminar e posterior desenvolvimento fundamentado. Procedeu-se à primeira fase através de entrevistas exploratórias, sessão com focus group e levantamento comparativo de soluções existentes. A análise qualitativa de resultados da fase de exploração permitiu confirmar a pertinência de uma plataforma lusófona. Constatou-se particular incidência dos avaliadores sobre os capítulos de análise financeira e estudo de mercado. Verificou-se a pertinência de estruturas de plano recomendadas e conteúdos didáticos interativos, partilhados por entidades especialistas, com vista à transposição de barreiras comunicacionais e conceptuais para empreendedores que não disponham de formação prévia nas áreas de gestão, marketing, análise e projeção financeira.

Palavras-chave: Plano de Negócio. Software as a Service. Comunicação multimídia.

\begin{abstract}
The object of study consists in a web service for interactive and tutored conception of business plans. The action-research-development methodology is applied in two stages: preliminary exploration and asserted development. The first stage took place through exploratory interviews, a focus group session and the comparative acknowledgement of existing solutions. The qualitative analysis of the exploration stage results supplied confirmation towards the relevance of a Portuguese-speaking community oriented platform. Results indicated that reviewers show particular concern for the financial analysis and market study chapters of the business plan. The availability of specialist-driven recommended plan
\end{abstract}

ANIMUS R. Interamericana de Comunicação Midiática, http://www.ufsm.br/revistas E-ISSN 2175-4977, v. 11, n. 21, Jan-Jun(2012) 
structures and insightful learning multimedia contents was verified as a focal point towards the transposition of communicational and conceptual barriers withholding entrepreneurs who lack background knowledge of management, marketing and financial analysis.

Key words: Business Plan. Software as a Service. Multimedia Communication.

\section{Resumen}

El estudio tiene como objeto establecer un servicio web para el diseño interactivo y tutorizado de planes de negocio. La metodología de investigación-acción-desarrollo contempla dos fases: la de exploración preliminar y el desarrollo fundamentado. La fase de exploración se realizó mediante la aplicación de entrevistas y de sesiones con grupos de enfoque, así como con el estudio comparativo de las posibles soluciones. El análisis cualitativo de los resultados de la fase de exploración confirmó la pertinencia de una plataforma lusófona. Se demostró la atención especial dada por los evaluadores a los capítulos de análisis financiero y a los estudios de mercado. Se hizo evidente que la disposición de estructuras recomendadas para el plan y los contenidos multimedia educativos se presentan como recursos muy ventajosos cuando son compartidos por las entidades de expertos, con el fin de transponer las barreras conceptuales y comunicativas para los empresarios que no tienen formación previa en gestión, marketing, análisis y proyección financiera.

Palabras clave: Plan de Negocio. Software as a Service. Comunicación Multimedia.

Esta obra está licenciada sob uma Licença Creative Commons

\section{CONTEXTUALIZAÇÃO DO PROBLEMA}

De acordo com o Relatório Estatístico Anual de 2011 do INPI ${ }^{1}$, “foram apresentados 772 pedidos de invenções, o que corresponde a um aumento de 18\% face ao ano anterior”. A inovação tem marcado uma presença crescente nos objetivos das Instituições de Ensino, Investigação e Desenvolvimento portuguesas, embora se mantenha ainda abaixo da média europeia segundo o European Innovation Scoreboard (2011, p.7). Em contrapartida, a análise comparativa da criação de empresas em Portugal e Espanha elaborada por Sarmento e Nunes (2011, p.28) salienta que “as taxas de registro de novas empresas são inferiores à média da UE”, constatando-se “menor dinâmica do registro de novas empresas a nível ibérico”.

\footnotetext{
${ }^{1}$ Relatório Estatístico Anual, Instituto Nacional da Propriedade Industrial, 2011. Disponível em $<$ http://www.marcasepatentes.pt/files/collections/pt_PT/4/70/Relatório\%20Estatístico\%20Anual_2011.pdf>. Acesso a 30 jun 2012.
} 
Entidades governamentais, institucionais e associações públicas e/ou privadas difundem diversos programas de incentivo à inovação e empreendedorismo, como se verifica pelo POFC do QREN ${ }^{2}$, os programa FINICIA ${ }^{3}$ e FINICIA JOVEM em parceria com o IPJ $^{4}$, a par de múltiplos concursos de ideias e ações de formação via ANJE $^{5}$, IAPMEI ${ }^{6}$ e Programa Estratégico para o Empreendedorismo e a Inovação “+e+i”

De igual forma, proliferam os concursos para jovens empreendedores copatrocinados por investidores institucionais e empresas particulares, destacando-se o "ISCTE-MIT Venture Competition" 8 e o "Prémio SIM [à Criatividade]” da Samsung9 .

Almejando a reabilitação de cidadãos desempregados, realiza-se também o programa de criação de empresa própria ao abrigo do $\operatorname{IEFP}^{10}$, cuja página online disponibiliza igualmente uma listagem de outros apoios à criação do próprio emprego ou empresa.

O cruzamento dos recursos disponíveis com as supracitadas estatísticas de criação de empresas incitou suspeitas quanto ao que poderia impedir os potenciais empreendedores portugueses de concorrer com a empresa, viabilizando a distribuição das suas invenções ou projetos de sustentabilidade.

\footnotetext{
${ }^{2}$ Concursos abertos no Programa Operacional de Factores de Competitividade, QREN. Disponível em $<$ http://www.pofc.qren.pt/concursos/concursos-abertos >. Acesso a 30 jun. 2012.

${ }^{3}$ Apresentação do Programa FINICIA, IAPMEI. Disponível em <http://www.iapmei.pt/iapmeimstplindex.php?msid=12>. Acesso a 30 jun 2012.

${ }^{4}$ Eixos FINICIA Jovem apresentados na seção de Emprego e Empreendedorismo, IPJ. Disponível em $<$ http://juventude.gov.pt/Emprego/Paginas/default.aspx>. Acesso em 30 jun 2012.

${ }^{5}$ Divulgação atualizada de concursos de ideias e apoios ao empreendedorismo na página oficial, ANJE. Disponível em <http://www.anje.pt>. Acesso a 30 jun 2012.

${ }^{6}$ Divulgação de eventos e concursos na página oficial do Instituto de Apoio às Pequenas e Médias Empresas e à Inovação, IAPMEI. Disponível em <http://www.iapmei.pt>. Acesso a 30 jun 2012.

${ }^{7}$ Divulgação de atividades na página oficial do programa, $+\mathrm{e}+\mathrm{i}-$ Programa Estratégico para o Empreendedorismo e a Inovação. Disponível em <http://www.ei.gov.pt>. Acesso a 30 jun 2012.

${ }^{8}$ Divulgação de concursos e resultados atuais na página ISCTE-IUL MIT Portugal, MIT Portugal - IEI. Disponível em <http://mitportugal-iei.org/>. Acesso a 30 jun 2012.

${ }^{9}$ Página oficial de apresentação do concurso de 2012, SIM à criatividade by Samsung. Disponível em $<$ http://www.simacriatividade.com/>. Acesso a 30 jun 2012.

10 "Programa de Apoio ao Empreendedorismo e à Criação do Próprio Emprego" e listagem de outras oportunidades de "apoios à criação do próprio emprego ou empresa”, IEFP. Disponível em $<$ http://www.iefp.pt/apoios/candidatos/CriacaoEmpregoEmpresa/Paginas/PróprioEmpregoEmpresa.aspx> . Acesso a 30 jun 2012.
} 
Um elemento mantém a sua presença como requisito em todas as ações de apoio e financiamento: o plano de negócio. Pinson (2001) explicita que um plano de negócio devidamente elaborado irá evidenciar o caminho lucrativo para dado negócio, bem como providenciará a documentação essencial para que um investidor possa facultar financiamento externo, caso seja necessário. Torna-se óbvia a pertinência deste documento nos diversos programas de incentivos, mas questiona-se o seu peso na taxa de desistências, nos números invisíveis de possíveis concorrentes que, por acreditarem não possuir os conhecimentos necessários para concessão de tal documento, não avançam com os seus projetos. Não se coloca em causa a absoluta necessidade de estudo prévio da viabilidade de um negócio para a sua implementação: trata-se de uma questão de fomento da autoconfiança, apreensão de conceitos especializados e transposição de conhecimentos práticos num documento coerente e válido aos olhos de especialistas.

\section{OBJETIVOS E LIMITAÇÕES DO ESTUDO}

Na génese do presente estudo verificam-se duas questões, de cariz exploratório: 1) Quais os maiores entraves que se colocam a empreendedores lusófonos sem repertório de gestão empresarial e/ou projeção financeira na elaboração do plano de negócio? e 2) Quais são as funcionalidades fulcrais na comunicação de conceitos e aquisição de competências na planificação de negócios mediada por computador?. Com vista a obter resposta a estas questões, traçaram-se os seguintes objetivos preliminares:

- verificar a afetação do plano de negócios na criação de novas empresas e/ou na participação de jovens empreendedores nos programas de incentivos disponíveis;

- averiguar quais as seções fundamentais aos olhos dos avaliadores e investidores;

- averiguar quais as seções mais desafiantes para empreendedores iniciados ou alheios à formação de gestão e análise financeira;

- efetuar um levantamento de ferramentas multimídia atuais que partilhem o intuito de elaboração mediada do plano ou ensino dos conceitos que lhe são inerentes;

- identificar os pontos fracos das ferramentas existentes e planificar um sistema que colmate tais lacunas, tornando-se mais acessível ao público lusófono. 
A exploração preliminar da temática atua como suporte para a definição da estrutura e desígnio funcional do serviço web PNO - Plano de Negócios Online ${ }^{11}$. A publicação desta plataforma visa responder a uma questão de cariz interpretativo: Qual o impacto dos novos media interativos na transposição das barreiras concpetuais e cognitivas inerentes à primeira experiência de elaboração de um plano de negócios? Depreendem-se como objetivos finais:

- $\quad$ analisar a eficácia e eficiência dos módulos funcionais de apoio ao utilizador nos seus diferentes formatos visuais e contextos de apresentação e/ou utilização;

- avaliar a performance do utilizador face às ferramentas disponibilizadas para concretização de cada tarefa, almejando anotar falhas de usabilidade e/ou concepção da experiência de utilização;

- por último e com maior relevância, medir as taxas de satisfação na tradução e apreensão dos conceitos por parte dos utilizadores iniciados ou alheios à formação em gestão e análise financeira.

Como produto, o serviço idealizado debater-se-ia com as adversidades inerentes à sua ampla concorrência, sobretudo no que diz respeito a soluções de software comercial desenvolvidas por especialistas na área da gestão, planeamento e projeção financeira. Em contrapartida, a plataforma a implementar apresenta-se como um objeto de investigação, maioritariamente focado na transposição de barreiras comunicacionais possivelmente impostas pelo discurso especialista face a destinatários neófitos, inexperientes. Posto isto, depreenderam-se como limitações do estudo:

- o carácter abrangente do público-alvo - todos os empreendedores inexperientes sem formação especializada em gestão e projeção financeira;

- a inexistência de dados científicos relacionados com a literacia digital da população em estudo, podendo fracos conhecimentos na óptica do utilizador interferir com a fruição da plataforma;

\footnotetext{
${ }^{11}$ A designação abreviada PNO, bem como a designação completa Plano de Negócio Online é de cariz temporário, na medida em que se trata de um projeto em curso, poderá surgir a necessidade de redefinir a sua designação.
} 
- a necessidade de implementação da plataforma mediante constrangimentos temporais, que poderá resultar num produto em fase “alfa” (com possíveis inconsistências funcionais), comprometendo os resultados;

- o lançamento da plataforma com conteúdos didáticos superficiais, não comportando o seu potencial total na disponibilização de estudos de caso e dicas de especialistas, por restrições temporais naturais ao enquadramento acadêmico.

Em plena consciência das limitações identificadas, almeja-se salvaguardar a essência funcional do objeto de estudo, desbravando o caminho para considerações pertinentes que possam dar lugar a uma otimização da plataforma e acréscimo dos seus conteúdos por parte de entidades especialistas. A equipe de desenvolvimento é formada por profissionais na área das novas tecnologias e comunicação multimídia, não da área de economia e gestão. Este perfil de formação é considerado um trunfo face às ferramentas existentes, pois obriga à concessão de uma plataforma versátil, pronta a receber conteúdos em aberto de diversas entidades gestoras e especialistas, não se restringindo a um único guião e/ou template estrutural.

\section{METODOLOGIA}

Tendo por objeto de estudo uma aplicação multimídia distribuída online, considerouse pertinente a metodologia de investigação-ação, complementada por métodos de investigação-desenvolvimento.

A investigação-ação assume-se num contexto de aplicação prática que, diferindo das ciências sociais convencionais, almeja gerar novo conhecimento por meio da implementação efetiva das mudanças almejadas ou preconizadas pelo estudo (HUANG, 2010, p. 93).

A fase de desenvolvimento aproxima-se da metodologia de investigação experimental (KUMAR, 2010, p. 100), onde se assume o baixo índice de criação de empresas como problema, causado pela insuficiência de repertório em economia e gestão e prossegue-se ao desenvolvimento de experiências - implementação e teste de módulos funcionais - almejando obter diferentes efeitos. Neste caso, o processo experimental almeja o efeito de concretização satisfatória de um plano de negócios válido, por meio de recursos multimídia interativos de apoio ao seu preenchimento. 
A exequibilidade dos objetivos propostos viabilizou-se através da divisão do processo de investigação em duas fases. A primeira fase, de carácter exploratório, possibilita a concretização dos objetivos preliminares e constrói os alicerces dedutivos para a segunda fase, de desígnio funcional, desenvolvimento, lançamento e teste da plataforma.

\subsection{Primeira fase: Exploração}

O presente artigo incide sobre os resultados da primeira fase e expõe as considerações precursoras à concessão efetiva da plataforma. Para obtenção de dados preliminares recorreuse a i) entrevistas exploratórias, discussão com ii) focus group, iii) levantamento das ferramentas atualmente disponíveis (Software, serviços e/ou plataformas web) e comparação das funcionalidades disponibilizadas.

\subsubsection{Entrevistas exploratórias}

O projeto de investigação vigente insere-se no contexto acadêmico do Mestrado em Comunicação Multimídia da Universidade de Aveiro (UA). A UA comporta atualmente nas suas infraestruturas uma incubadora de empresas:

A Incubadora de Empresas da Universidade de Aveiro (IEUA) incentiva e
promove a criação, o desenvolvimento e o crescimento sustentado de
projectos empresariais inovadores e de base tecnológica, através da
disponibilização de espaços individuais e partilhados, de um conjunto de
serviços, e de uma rede de parceiros e de profissionais orientados para a
criação de valor e para o sucesso das empresas incubadas. ${ }^{12}$

A disponibilidade da IEUA foi considerada como uma vantagem para recolher relatos de jovens empreendedores que tivessem elaborado um plano de negócio com o intuito de concorrer com o seu projeto à incubadora, cujos requisitos se refletem de igual forma nos diversos sistemas de incentivo enumerados na contextualização do problema de investigação. Neste contexto, os entrevistados selecionados foram considerados como "testemunhas privilegiadas” (QUIVY, 1992, p. 71) no âmbito das entrevistas exploratórias que, segundo Quivy, “servem para encontrar pistas de reflexão, ideias e hipóteses de trabalho”.

\footnotetext{
${ }^{12}$ Conceito da Incubadora de Empresas da Universidade de Aveiro, IEUA. Disponível em <https://www.ua.pt/ieua/PageText.aspx?id=13810>. Acesso a 30 jun 2012.
} 
Considerou-se igualmente apropriado entrevistar o Diretor da IEUA, tendo em vista o parecer de um órgão experiente na avaliação de planos de negócio.

Considerou-se pertinente a preparação de entrevistas semiestruturadas, pois:

combinam perguntas abertas e fechadas, onde o informante tem a possibilidade de discorrer sobre o tema proposto. O pesquisador deve seguir um conjunto de questões previamente definidas, mas ele o faz em um contexto muito semelhante ao de uma conversa informal. (...) Esse tipo de entrevista é muito utilizado quando se deseja delimitar o volume das informações, obtendo assim um direcionamento maior para o tema, intervindo a fim de que os objetivos sejam alcançados (BONI, 2010, p. 75).

Posta a seleção de dois perfis de testemunhas distintos - jovens empreendedores e diretor da incubadora - foram elaborados dois guiões de entrevista, permitindo encaminhar cada entrevista de forma aberta, mas orientada a objetivos concretos de exploração.

Foram entrevistados três empreendedores com negócios incubados na IEUA, bem como o Diretor responsável pela Incubadora de Empresas. O desfeche desta recolha é apresentado na secção de análise de resultados.

\subsubsection{Focus Group}

A exploração por meio de focus group consiste numa técnica de entrevista em grupo ao abrigo da qual vários participantes de um determinado contexto social podem ser questionados em simultâneo (MORGAN, 1993, p. 20), resultando numa discussão moderada cujo entrevistador se enquadra no papel de moderador, observador e pode, opcionalmente, intervir. Segundo Morgan, esta abordagem permite recolher uma maior amplitude de opiniões ou experiências, constituindo uma vantagem devido à interação entre intervenientes, que providencia uma base explicita para exploração (1993, p. 17);

À semelhança da colaboração da IEUA como base de incidência das entrevistas exploratórias, a entrevista do focus group deu-se também num contexto de oportunidade e conveniência: a UNAVE, Associação para a Formação Profissional e Investigação da Universidade de Aveiro, realizou uma formação intitulada "Empreendedorismo - O Plano de Negócio, a Viabilidade do Investimento e o Financiamento do Projeto”, cuja pertinência se demarcou imediatamente no contexto desta investigação. 
Procedeu-se assim ao convite dos formandos para uma sessão informal de apresentação do projeto de investigação PNO, com vista a aferir a pertinência do serviço para sujeitos motivados na apreensão de conceitos inerentes ao empreendedorismo e concessão de um plano de negócios. Embora o grupo se tenha revelado diminuto - compareceram apenas três dos formandos - procedeu-se de igual forma à gravação audiovisual da apresentação e discussão aberta de dúvidas eminentes na elaboração de um plano de negócio, experiências com ferramentas existentes e conhecimentos de atividades de apoio ao empreendedorismo e criação de empresa, pontos sintetizados na análise de resultados.

\subsection{Segunda fase: Implementação, lançamento e avaliação}

A segunda fase é o cerne da metodologia de investigação-ação-desenvolvimento, focando a concretização dos objetivos finais mencionados na seção 2 do presente artigo. A estruturação do serviço PNO web e respetivas funcionalidades será uma consequência das considerações resultantes da primeira fase de investigação. Na fase de lançamento, procederse-á à disponibilização da plataforma a sujeitos de teste motivados pelas suas funcionalidades.

A avaliação da plataforma usufruirá de uma metodologia própria, cujos instrumentos de recolha de dados permanecem ainda em definição iterativa. Não obstante, prevê-se a realização de uma avaliação heurística, "um método informal de análise de usabilidade onde um dado número de avaliadores são apresentados a uma interface e lhes é pedido o seu comentário” (NIELSEN, 1990, p. 249).

Enquanto a avaliação heurística permite identificar inconsistências ao nível do design de interface da aplicação, bem como determinar falhas na experiência do utilizador, os objetivos concretos da investigação incindem principalmente sobre o sucesso na transposição de barreiras à apreensão dos conceitos inerentes à planificação do negócio, pelo que é necessário determinar instrumentos de recolha de dados que possibilitem avaliar o grau de satisfação dos utilizadores, bem como a taxa de sucesso na concessão de planos mediada pela plataforma. O inquérito por questionário destaca-se como possível instrumento de recolha de dados, enquanto a validação de planos selecionados por parte de especialistas deve também ser considerada para medição da taxa de sucesso. 
Esta fase tomará início posteriormente à publicação do presente artigo, ficando por determinar futuramente o resultado da sua aplicação prática.

\section{RESULTADOS DA FASE DE EXPLORAÇÃO}

Assumindo os objetivos traçados para a exploração preliminar da temática, coloca-se a incidência do estudo sobre as experiências e comportamentos de sujeitos num determinado contexto social, apelando a uma pesquisa de caráter qualitativo centrada em "produzir resultados não alcançados através de procedimentos estatísticos ou de outros meios de quantificação”, onde “alguns dados podem ser quantificados”, mas “o grosso da análise é interpretativa” (STRAUSS, 2008, p. 23).

Strauss salienta três componentes inerentes à pesquisa qualitativa: 1) dados, 2) procedimentos e 3) relatórios escritos (2008, p. 24). A fase de exploração em análise teve por dados os testemunhos resultantes das entrevistas exploratórias e discussão com focus group, bem como referências da consulta online de ferramentas multimídia atualmente disponibilizadas para concessão de planos de negócio mediada por computador.

No que diz respeito às entrevistas exploratórias e focus group, o procedimento consistiu na transcrição dos registos audiovisuais das interlocuções, identificação de conceitos-chave e categorização de tópicos recorrentes, cujas ocorrências e relações foram “codificadas” (STRAUSS, 2008, p. 24) por meio do software de análise qualitativa de conteúdos NVivo (BAZELEY, 2007). O levantamento do estado da arte no que respeita às funcionalidades de ferramentas multimídia de planificação de negócios foi efetuado de forma estruturada, através da elaboração de uma tabela comparativa.

Com estes procedimentos almeja-se aferir uma "teoria fundamentada”, “derivada de dados, sistematicamente reunidos e analisados” (STRAUSS, 2008, p. 25) em prole da segunda fase de desenvolvimento da investigação.

\subsection{Resultados das entrevistas exploratórias individuais}

Dos três empreendedores entrevistados, dois possuíam formação avançada em gestão, economia e/ou análise financeira. Um dos entrevistados obteve esses conhecimentos por meio 
de um curso profissionalizante do ensino secundário, enquanto o outro prosseguiu de uma licenciatura em engenharia civil para uma pós-graduação em gestão de negócios. Os três empreendedores abordaram engenharia e/ou formação tecnológica no seu perfil acadêmico, o que compactua com a obrigatoriedade de cariz tecnológico para projetos submetidos à incubadora de empresas da Universidade de Aveiro.

Era um dado adquirido que todos os empreendedores se viram forçados a apresentar um plano de negócios à incubadora de empresas, embora nenhum dos entrevistados tenha recorrido à revisão prévia do seu plano por parte de consultores especialistas. Não obstante, todos mencionaram a revisão por parte de colegas e familiares.

Os dois entrevistados com formação de base de gestão e projeção financeira mencionaram revisões periódicas dos seus planos de negócio, com vista ao ajustamento dos objetivos das respetivas empresas e produtos. Já o entrevistado sem formação de base de gestão confessou ter concebido o plano de negócios por obrigatoriedade e não rever o plano de negócios no contexto ativo da empresa. O mesmo entrevistado ressalvou, no entanto, que elabora um planeamento simplificado focado apenas em projeções para produtos isolados.

Dois dos entrevistados tomaram conhecimento dos templates de plano de negócios fornecidos pela $\mathrm{ANJE}^{13}$ e IAPMEI ${ }^{14}$, sendo que um deles apenas tomou os templates como referência e elaborou uma outra solução adaptada apenas às suas necessidades. O entrevistado com o grau mais elevado de formação em gestão confessou desconhecer os templates fornecidos pelas associações supramencionadas e afirmou elaborar cada plano de negócios à medida da sua audiência.

Seguidamente apresentam-se tabelas de exposição de tópicos recorrentes em questões de resposta aberta, colocadas não só aos três empreendedores da IEUA, mas também ao diretor da IEUA, compondo assim uma população de quatro entrevistados. É considerada apenas uma ocorrência por cada sujeito.

Tabela 1 - Tópicos e/ou conceitos referentes às seções mais relevantes do plano de negócio

\footnotetext{
${ }^{13}$ Modelo de Plano de Negócio, ANJE. Disponível em $<$ http://www.anje.pt/system/files/items/67/original/MODELO_TIPO_PN.xls>. Acesso a 30 jun 2012.

${ }^{14}$ Modelo de Plano de Negócio FINICIA, IAPMEI. Disponível em

$<$ http://www.iapmei.pt/resources/download/Finicia_pn_v11a_2010.xls?PHPSESSID=54b4c695870bfd4cff8a40b 8f8b2f2d2>. Acesso a 30 jun 2012.
} 


\begin{tabular}{|l|c|}
\hline \multicolumn{1}{|c|}{ Tópico/Conceito } & Ocorrências \\
\hline Estudo de Mercado & 4 \\
\hline Análise Financeira & 3 \\
\hline Sumário Executivo & 1 \\
\hline
\end{tabular}

Fonte: Codificação de testemunhos das entrevistas exploratórias.

Conforme a Tabela 1, quando questionados acerca dos pontos de maior exigência na elaboração do plano de negócio, todos os entrevistados salientaram o estudo de mercado e viabilidade do produto, acrescentando a pertinência de elaboração interativa e assistida de gráficos elucidativos quanto à análise e posicionamento de mercado.

Três dos entrevistados mencionaram a relevância da projeção financeira, mas nenhum destes apresentou o preenchimento dos pressupostos e cálculos como um obstáculo, devido à sua experiência com software de cálculo como o Microsoft Office Excel.

O sumário executivo foi um ponto de enfâse por parte do diretor da IEUA, dada o seu carácter self-contained - à semelhança dos abstract nos artigos científicos - na transmissão das ideias e previsões principais do negócio.

Tabela 2 - Tópicos e/ou conceitos referentes à falhas comuns no planeamento de negócios

\begin{tabular}{|l|c|}
\hline \multicolumn{1}{|c|}{ Tópico/Conceito } & Ocorrências \\
\hline Análise Financeira demasiado otimista & 3 \\
\hline Estudo de Mercado insuficiente & 2 \\
\hline Potencial de Lucro sobrestimado & 1 \\
\hline
\end{tabular}

Fonte: Codificação de testemunhos das entrevistas exploratórias.

Ao apreender os pontos de maior incidência de falhas, tornou-se possível para a equipe de desenvolvimento delinear estratégias para alertar os utilizadores do PNO quanto a estes erros comuns e às suas possíveis resoluções. Depreendeu-se também uma preocupação maior em assegurar uma análise financeira realista, em paralelo com a elaboração completa e cuidada do estudo de mercado.

Tabela 3 - Tópicos e/ou conceitos lançados como sugestões funcionais

\begin{tabular}{|l|c|}
\hline \multicolumn{1}{|c|}{ Tópico/Conceito } & Ocorrências \\
\hline Automatização dos cálculos de análise e projeção financeira & 4 \\
\hline Processo tutorado, à semelhança de tarefas em e-Learning, para inexperientes & 4 \\
\hline
\end{tabular}




\begin{tabular}{|l|c|}
\hline Dicas contextualizadas para preenchimento de cada seção & 4 \\
\hline Elaboração interativa e assistida de gráficos de posicionamento de mercado & 3 \\
\hline Alertas para seções relevantes negligenciadas ou indevidamente preenchidas & 3 \\
\hline Fornecimento de exemplos e estudos de caso nas diversas indústrias e capítulos & 3 \\
\hline Exportação do documento final em diversos formatos: .doc,.pdf,.xls,.ppt & 3 \\
\hline Formatação do documento e recolha de seções mediante público-alvo & 2 \\
\hline Automatização da dedução de perspectivas de mercado & 1 \\
\hline Customização da apresentação visual do documento final & 1 \\
\hline
\end{tabular}

Fonte: Codificação de testemunhos das entrevistas exploratórias.

A análise da Tabela 3 permitiu a adenda e otimização da especificação funcional do serviço PNO, coadunando com as funcionalidades planeadas previamente à realização das entrevistas. De notar que os entrevistados foram contextualizados quanto às funcionalidades previstas para o serviço, tendo expressado novas sugestões ou, no caso dos conceitos de maior ocorrência, comunicado forte aprovação pela implementação de determinada funcionalidade.

O entrevistado com maior formação de gestão e o diretor da IEUA partilharam alguns conselhos complementares, enumerados seguidamente:

- para um potencial investidor ou entidade de financiamento, o ponto fulcral do plano de negócio é o potencial de lucro, projetado na análise financeira e suportado pelo estudo de mercado;

- $\quad$ para uma Incubadora, a capacidade de concretização do projeto e aptidões dos promotores são de maior importância na aprovação do plano;

- o plano de negócios deve ser encarado como um Curriculum Vitae dos promotores e do seu negocio;

- cada audiência dispõe de diferentes disponibilidades e interesses face ao plano de negócios: o promotor deve selecionar as informações contidas de acordo com a sua audiência e assegurar que o plano de negócio pode ser apreendido no menor intervalo temporal possível em situações de pitch;

- um utilizador experiente, com repertório especializado em gestão, deveria poder usufruir da plataforma em modo avançado, omitindo o formato tutorado;

- um especialista com conhecimentos avançados de cálculo financeiro poderá sentir-se mais confortável na elaboração da análise financeira por meio de folhas de cálculo em vez de se restringir às potencialidades da plataforma. 


\subsection{Resultados da sessão com focus group}

O início da sessão contou com a equipe de investigação em pleno, tendo sido apresentados os objetivos principais do objeto de estudo. A discussão teve por moderador o elemento da equipe responsável pela especificação funcional e implementação técnica da plataforma, garantindo uma contextualização segura no que concerne às potencialidades e limitações do serviço.

Por muito prezada que tenha sido a interação com os três formandos que se disponibilizaram a participar na sessão, esta foi prejudicada não só pela fraca adesão de participantes, como também pela indisponibilidade da plataforma para apresentação prática aos intervenientes. A plataforma PNO foi apresentada conceptualmente $\mathrm{e}$ as suas funcionalidades foram enumeradas, com a exemplificação de algumas funcionalidades paralelas em algumas das aplicações expostas no levantamento de softwares similares.

Ressalva-se também os conhecimentos superficiais de gestão e projeção financeira por parte do moderador da discussão, que embora se tenha contextualizado devidamente, não poderia apresentar um parecer especialista face às especificidades da criação de uma empresa e envolvente aprofundada do panorama nacional de incentivos ao empreendedorismo. A sua área de incidência constitui-se pela Comunicação Multimídia e Novas Tecnologias de Comunicação, providenciando maior contextualização na exequibilidade funcional e potencial comunicacional da plataforma.

Dos três formandos que compareceram à sessão, um encontrava-se na faixa etária acima dos 50 anos, enquanto os restantes dois se encontravam na faixa etária entre os 20 e os 30 anos.

A disparidade de repertórios verificou-se ao constatar que um dos formandos mais jovens se encontrava a estudar gestão e a trabalhar em paralelo com instituições de apoio ao empreendedorismo, enquanto o outro apenas participara na formação com vista a iniciar-se na apreensão dos conceitos para possível criação de empresa a longo prazo. O formando de maior idade manifestou claro interesse em criar um negócio próprio, embora tenha também confessado a necessidade de aprendizagem aprofundada dos conceitos de contabilidade, gestão e análise financeira, abordados sucintamente - ainda que de forma objetiva e sapiente durante a formação. 
A sessão resultou numa troca informal de dúvidas de alguns dos intervenientes face à concretização da análise financeira e composição do plano de negócios, bem como no lançamento livre de sugestões para a plataforma proposta. Dado o paralelismo com as sugestões recolhidas das entrevistas individuais, salienta-se essencialmente a menção enfatizada da exportação do plano em formato passível de ser apresentado através de pontoschave, à semelhança de uma apresentação em PowerPoint. Discutiu-se também o lançamento interativo de questões pertinentes ao promotor, cujas respostas serviriam de base de preenchimento automático para as diferentes seções do plano de negócio mediado pela plataforma.

O formando com experiência em participação e coordenação de programas de incentivo ao empreendedorismo ressalvou a presença de modelos de plano de negócio em quase todos os concursos lançados, com especial atenção à simplificação de cada modelo para melhor se adequar aos objetivos diretos de cada concurso.

O formando menos contextualizado com os conceitos básicos de gestão e projeção financeira esboçou dificuldades na apreensão dos modelos disponibilizados, especialmente no preenchimento de folhas de cálculo onde proliferam expressões associadas a jargão técnico e pressupostos financeiros sem quaisquer ajudas.

Ao observar o template fornecido pelo IAPMEI em conjunto, verificou-se a ressalva dos seus autores em aconselhar a presença de um consultor ou especialista em contabilidade e análise financeira no preenchimento do modelo de plano de negócio, possível entrave para empreendedores que não disponham dos recursos financeiros ou contatos necessários.

\subsection{Resultados do levantamento de aplicações similares}

O levantamento das ferramentas multimídia, serviços web e softwares similares existentes, potenciou a comparação de funcionalidades disponibilizadas e identificação de lacunas a colmatar pelo serviço visionado.

O método de levantamento consistiu na consulta de diversas fontes online, filtrando apenas aplicações nos idiomas Português e Inglês. No caso das aplicações em Português abrangeu-se software online e offline. Nas aplicações em Inglês, foi efetuada uma procura focalizada apenas em serviços web, dada a abundância de softwares offline e 
indisponibilidade de aquisição comercial das soluções empresariais encontradas em quaisquer dos idiomas.

Quadro 1 - Levantamento seletivo de softwares para concessão de planos de negocio mediada por computador

\begin{tabular}{|c|c|c|c|}
\hline SOFTWARE & $\begin{array}{l}\text { PROMOTOR } \\
\end{array}$ & ON/OFFLINE & IDIOMA \\
\hline A - LivePlan ${ }^{15}$ & PaloAlto Software & Online & EN - US \\
\hline B - BizPlan Builder ${ }^{16}$ & Jian Software & Online & EN - US \\
\hline C - Enloop ${ }^{17}$ & Enloop Inc. & Online & EN - US \\
\hline D - EasyPlan ${ }^{18}$ & Portal Plano de Negócios & Online & $\mathrm{PT}-\mathrm{BR}$ \\
\hline E - Plano de Negócio $2.0^{19}$ & Sebrae MG & Offline & $\mathrm{PT}-\mathrm{BR}$ \\
\hline F - Empreenda! $!^{20}$ & B2ML Sistemas, iOpen & Offline & PT - BR \\
\hline G - MakeMoney $10^{21}$ & Starta & Offline & PT - BR \\
\hline
\end{tabular}

Fonte: Cruzamento de diversas fontes, consultar notas de rodapé de cada software.

O serviço online LivePlan apresenta-se como um Best-Seller entre os seus concorrentes, tendo servido de referência primordial para o estudo vigente. Colocando-se a inviabilidade de aquisição e experimentação de todos os softwares, foi efetuado um levantamento com base na descrição de funcionalidades disponibilizada para cada aplicação.

Quadro 2 - Comparação de características funcionais divulgadas pelos softwares selecionados como referência

\begin{tabular}{|l|c|c|c|c|c|c|c|}
\hline \multicolumn{1}{|c|}{ FUNCIONALIDADE } & A & B & C & D & E & F & G \\
\hline Automatização de cálculos de análise financeira & $\mathrm{X}$ & $\mathrm{X}$ & $\mathrm{X}$ & & $\mathrm{X}$ & $\mathrm{X}$ & $\mathrm{X}$ \\
\hline Criação dinâmica de gráficos e tabelas de projeção financeira & $\mathrm{X}$ & $\mathrm{X}$ & $\mathrm{X}$ & & $\mathrm{X}$ & $\mathrm{X}$ & $\mathrm{X}$ \\
\hline Pressupostos financeiros editáveis & $\mathrm{X}$ & $\mathrm{X}$ & $\mathrm{X}$ & & $\mathrm{X}$ & & $\mathrm{X}$ \\
\hline Projeção financeira a 3 anos & $\mathrm{X}$ & $\mathrm{X}$ & $\mathrm{X}$ & & & $\mathrm{X}$ & $\mathrm{X}$ \\
\hline Projeção financeira a 5 anos & $\mathrm{X}$ & $\mathrm{X}$ & & & $\mathrm{X}$ & $\mathrm{X}$ & $\mathrm{X}$ \\
\hline
\end{tabular}

${ }^{15}$ Funcionalidades LivePlan, PaloAlto Software. Disponível em <http://www.liveplan.com/features/easy_financials>. Acesso a 30 jun 2012.

${ }^{16}$ Funcionalidades BizPlan Builder, Jian Software. Disponível em $<$ http://www.jian.com/features/business_plan_features.html>. Acesso a 30 jun 2012.

${ }^{17}$ Funcionalidades Enloop, Enloop Inc. Disponível em <http://www.enloop.com/plans_and_pricing>. Acesso a 30 jun 2012

${ }^{18}$ Ajuda do EasyPlan, Portal Plano de Negócios. Disponível em

<http://www.planodenegocios.com.br/www/index.php/easyplan-ajuda>. Acesso a 30 jun 2012.

${ }^{19}$ Descrição Plano de Negócio 2.0, Sebrae MG. Disponível em

$<$ http://www.sebraemg.com.br/BibliotecaDigital/VisualizarDocumento.aspx?CODIGO=52>.

Acesso a 30 jun 2012.

${ }^{20}$ Funcionalidades Empreenda!, B2ML Sistemas, iOpen. Disponível em

<http://www.empreendacomsucesso.com.br/empreenda/funcionalidades;jsessionid=1m6a4htbhglwe>.

Acesso a 30 jun 2012.

${ }^{21}$ Características e Recursos MakeMoney 10, Sarta. Disponível em <http://makemoney.starta.com.br/softwareplano-de-negocio/plano-de-negocio-evtec-inovacao/>. Acesso a 30 jun 2012. 


\begin{tabular}{|l|c|c|c|c|c|c|c|}
\hline Disponibilização de estrutura(s) de plano estandardizadas & $\mathrm{X}$ & $\mathrm{X}$ & $\mathrm{X}$ & & $\mathrm{X}$ & $\mathrm{X}$ & $\mathrm{X}$ \\
\hline Liberdade de personalização e reestruturação das seções do plano & $\mathrm{X}$ & $\mathrm{X}$ & & $\mathrm{X}$ & & & $\mathrm{X}$ \\
\hline Exportação do plano para formato ddoc e/ou .pdf & $\mathrm{X}$ & $\mathrm{X}$ & $\mathrm{X}$ & & & $\mathrm{X}$ & $\mathrm{X}$ \\
\hline Exportação do plano sintetizado apresentação em formato .ppt & & $\mathrm{X}$ & & & & & \\
\hline Exportação da análise financeira em formato .xls & & $\mathrm{X}$ & & & & & \\
\hline Instruções contextualizadas de preenchimento & $\mathrm{X}$ & $\mathrm{X}$ & $\mathrm{X}$ & $\mathrm{X}$ & $\mathrm{X}$ & $\mathrm{X}$ & $\mathrm{X}$ \\
\hline Exemplos de estudos de caso orientados às diferentes indústrias & $\mathrm{X}$ & $\mathrm{X}$ & $\mathrm{X}$ & $\mathrm{X}$ & & & $\mathrm{X}$ \\
\hline Exemplos de planos completos para referência & $\mathrm{X}$ & $\mathrm{X}$ & $\mathrm{X}$ & $\mathrm{X}$ & & & $\mathrm{X}$ \\
\hline Preenchimento automático dos campos de texto com exemplos prévios & $\mathrm{X}$ & $\mathrm{X}$ & $\mathrm{X}$ & & & & \\
\hline Instruções e dicas em formato vídeo & $\mathrm{X}$ & $\mathrm{X}$ & & & & & $\mathrm{X}$ \\
\hline Instruções e dicas em formato textual & $\mathrm{X}$ & $\mathrm{X}$ & $\mathrm{X}$ & $\mathrm{X}$ & $\mathrm{X}$ & $\mathrm{X}$ & $\mathrm{X}$ \\
\hline Possibilidade de colaboração e elaboração de planos em equipa & $\mathrm{X}$ & $\mathrm{X}$ & $\mathrm{X}$ & $\mathrm{X}$ & & & \\
\hline Possibilidade de validação e comentário a seções específicas do plano & $\mathrm{X}$ & & & & & & \\
\hline Partilha imediata do plano em formato web & $\mathrm{X}$ & $\mathrm{X}$ & $\mathrm{X}$ & $\mathrm{X}$ & & & \\
\hline Definição de diferentes níveis de acesso e privacidade do plano & $\mathrm{X}$ & & $\mathrm{X}$ & & & & \\
\hline Confidencialidade dos dados inseridos & $\mathrm{X}$ & $\mathrm{X}$ & & & $\mathrm{X}$ & $\mathrm{X}$ & $\mathrm{X}$ \\
\hline Mecanismos de validação do plano & & $\mathrm{X}$ & $\mathrm{X}$ & & & & $\mathrm{X}$ \\
\hline Certificação de avaliação obtida por plano na aplicação & & & $\mathrm{X}$ & & & & \\
\hline Relatório de resultados comparativos com médias da indústria & & & $\mathrm{X}$ & & & & \\
\hline
\end{tabular}

Fonte: Cruzamento de diversas fontes, consultar notas de rodapé dos softwares referenciados.

A comparação apresentada no Quadro 2 comporta uma margem de erro considerável dada a ausência de testes experimentais das aplicações que comprovem as funcionalidades divulgadas. Esta margem de erro pode também prejudicar o software referenciado, pois as fontes de informação podem conter listas desatualizadas das funcionalidades da aplicação.

Não obstante, o enfoque deste levantamento e análise comparativa é salientar o conjunto de funcionalidades fulcrais à concessão viável de um plano de negócios, tendo por intermédio um sistema informático. No caso da plataforma PNO a capacidade de distribuição online é imperativa por motivos de acesso comunitário às diferentes entidades e utilizadores do sistema, possibilitando também atualizações iterativas e coletivas do software.

Ao observar o Quadro 2 torna-se possível efetuar um cruzamento com os resultados das entrevistas exploratórias e focus group. O capítulo de análise financeira, bem como a elaboração gráfica de estudos de mercado, apresentam-se como funcionalidades de grande incidência, a par das instruções e dicas em formato textual.

A automatização de cálculos e projeção financeira dinâmica constituem um fator diferenciador entre soluções comerciais especializadas - como o LivePlan e Enloop - e soluções gratuitas meramente focadas no preenchimento de capítulos textuais do plano de negócio, como é o caso do EasyPlan. 
A contextualização das dicas de preenchimento apresenta-se como um requisito presente em todas as referências, não invalidando a disponibilização de estudos de caso e planos de negócio exemplares, também mencionados pelos entrevistados.

No que diz respeito aos formatos de divulgação de conteúdos didáticos, verifica-se a incidência primordial de conteúdos em formato textual, com ocorrências de conteúdos em formato vídeo em aplicações de cariz comercial, possivelmente suportadas por orçamentos de maior escala. Os vídeos disponibilizados são de consumo privado para clientes e figuram frequentemente especialistas de renome, apresentados nas páginas oficiais do software. No caso do serviço LivePlan, Tim Berry é o porta-voz e mentor em todos os passos da elaboração do plano de negócios.

Quanto à exportação do documento formal, a grande maioria das soluções disponibiliza um ficheiro em formato .pdf para impressão ou até mesmo em formato .doc para edição posterior. Apenas a solução BizPlan Builder da Jian Software potencia a exportação em formatos .ppt e .xls, mencionados pelos entrevistados e intervenientes do focus group.

Embora três das soluções detenham mecanismos de validação dos dados preenchidos e plano resultante, a solução Enloop aparenta ser a única que disponibiliza uma certificação pública consultável da performance do plano de negócio e relatório de resultados comparativos às médias contabilísticas de concorrentes da mesma indústria.

A confidencialidade dos dados inseridos pode apresentar uma preocupação primordial para promotores que temam a divulgação precoce e apropriação indevida do seu projeto de negócio. Esta característica é óbvia em todas as aplicações offline, pois os dados residem apenas no sistema operativo do promotor, que se deve encarregar de proteger o acesso à sua conta de utilizador. No caso dos serviços online, esta tarefa é de maior dificuldade e mesmo serviços que asseguram as melhores práticas de segurança, como o LivePlan, são vulneráveis a ataques cibernéticos que podem não só corromper os dados, como eliminá-los ou divulgalos publicamente por exploração de falhas de segurança.

Em contrapartida, verifica-se em simultâneo a disponibilização de meios de colaboração e elaboração em equipa de planos de negócio, dispostos para validação por pares e consultores especialistas. Esta funcionalidade mostra-se especialmente viável em serviços web e em alguns softwares offline de integração em redes empresariais de confiança. 
Embora várias soluções possibilitem a alteração da estrutura predefinida do plano de negócios, nenhuma aparenta possibilitar a exportação de diferentes estruturas resultantes de um só plano de negócios, o que beneficiaria a adaptação do projeto a diferentes audiências.

\section{CONSIDERAÇÕES DA FASE EXPLORATÓRIA}

O cariz exploratório da primeira fase de investigação permitiu definir concretamente e aprofundar os objetivos finais do objeto de estudo, a plataforma PNO.

A análise qualitativa dos resultados das entrevistas exploratórias, bem como da sessão com focus group, permitiu verificar a forte afetação do plano de negócios na criação de novas empresas, averiguar quais as seções fundamentais do plano aos olhos dos avaliadores e as mais desafiantes para os promotores iniciados. Considera-se que a análise e projeção financeira apresenta um grau elevado de jargão técnico e conceitos a apreender, constituindo não só uma componente fulcral para investidores, mas também um entrave cognitivo para empreendedores menos contextualizados com conceitos de economia, gestão e análise financeira. Em paralelo, o estudo de mercado comporta também várias especificidades da área de gestão e marketing, consagrando-se como elemento diferenciador de um bom plano de negócio aos olhos de um avaliador experiente. Esta componente pode prejudicar fortemente um promotor que negligencie a apreensão de conceitos básicos e apresentação de estudos de viabilidade econômica face à concorrência da sua indústria de atuação.

O cruzamento entre as sugestões funcionais dos entrevistados e o levantamento comparativo de funcionalidades disponibilizadas pelas soluções atualmente em vigor fomentou a compreensão de funcionalidades recorrentes - que não podem ser negligenciadas - e a dedução de funcionalidades em falta, nomeadamente:

- $\quad$ preenchimento auxiliado pela elaboração de perguntas objetivas, cujas respostas sucintas sirvam de ponto de partida para cada seção;

- registo de frases ou tópicos-chave em cada capítulo e/ou seção, potenciando o preenchimento automático do sumário executivo;

- possibilidade de exportação em diferentes formatos com estruturas díspares de conteúdos baseados no mesmo plano, adequadas às diferentes audiências do plano de negócio; 
- possibilidade de exportação automática de uma apresentação sucinta composta pelos tópicos-chave supracitados.

A exploração experimental do serviço LivePlan e abordagem superficial dos softwares igualmente enumerados permitiu também constatar que os conteúdos destas aplicações são frequentemente oriundos de um só interlocutor especialista, sendo elaborados aquando da concessão do software e, consequentemente, estagnados no tempo. Como resposta a esta limitação, considerou-se pertinente a concessão de um sistema de edição de conteúdos didáticos aberto a diversas fontes, caracterizado por:

- áreas de gestão de conteúdos para múltiplas entidades especialistas, com o potencial de partilha de estruturas de plano recomendadas, bem como de conteúdos didáticos facultados pela entidade tendo em vista os seus programas de incentivos e apoio;

- $\quad$ possibilidade de estruturação de tutoriais faseados, referenciados a cada seção da estrutura proposta;

- trechos de tutoriais compostos livremente por seções textuais, objetos multimídia embebidos e referências a conteúdos audiovisuais publicados em plataformas de streaming de acesso público ou controlado;

- da parte do empreendedor-utilizador, possibilidade de escolha da entidade de referência para elaboração de um novo plano, afetando as estruturas disponíveis e conteúdos didáticos disponibilizados.

As considerações supramencionadas permitiram alargar os horizontes de atuação do PNO, tornando-o numa ferramenta de igual utilidade para entidades de apoio ao empreendedorismo que frequentemente se vêm forçadas a "reinventar a roda” apenas para divulgar os seus modelos e conteúdos didáticos. Com o auxílio do sistema de edição de conteúdos para entidades, viabiliza-se uma modalidade de Specialist-Generated-Content, por oposição ao User-Generated-Content frequentemente associado a contribuições por parte de amadores criativos (KRUMM, 2008, p. 10), mas mantendo a componente de partilha comunitária.

A soma das considerações apresentadas no presente estudo possibilitou a transição do processo de investigação para a sua segunda fase, caracterizada pelo desenvolvimento consciente, estudado e devidamente fundamentado de um serviço facilitador da elaboração de 
um plano de negócios coerente, mediada por computador e de fruição na web para todos os membros da lusofonia. 


\section{REFERÊNCIAS}

BAZELEY, P. Qualitative data analysis with NVivo. Sage Publications Ltd, 2007. ISBN 1412921414.

BONI, V.; QUARESMA, S. J. Aprendendo a entrevistar: como fazer entrevistas em Ciências Sociais. Em Tese, v. 2, n. 1, p. 68-80, 2010. ISSN 1806-5023.

COMMISSION, E. The Innovation Union's performance scoreboard for Research and Innovation, The Innovation Union Scoreboard 20112011.

HUANG, H. B. What is good action research. Action Research, v. 8, n. 1, p. 93-109, 2010.

KRUMM, J.; DAVIES, N.; NARAYANASWAMI, C. User-generated content. Pervasive Computing, IEEE, v. 7, n. 4, p. 10-11, 2008. ISSN 1536-1268.

KUMAR, R. Research methodology: A step-by-step guide for beginners. Sage Publications Ltd, 2010. ISBN 1849203016.

MORGAN, D. L. Successful focus groups: Advancing the state of the art. Sage Publications, Inc, 1993. ISBN 0803948743.

NIELSEN, J.; MOLICH, R. Heuristic evaluation of user interfaces. 1990. ACM. p.249-256.

PINSON, L. Anatomy of a business plan: the step-by-step guide to building your business and securing your company's future. Out Of Your Mind... And Into The Mark, 2008. ISBN 0944205372.

SARMENTO, E.; NUNES, A. Criação de empresas em Portugal e Espanha: análise comparativa com base nos dados do Banco Mundial. CEEAplA-Centro de Estudos de Economia Aplicada do Atlântico. Portugal, 2011.

STRAUSS, A. L.; CORBIN, J. Pesquisa qualitativa: técnicas e procedimentos para o desenvolvimento de teoria fundamentada. Artmed, 2008. ISBN 853631043X.

QUIVY, R.; CAMPENHOUDT, L. V. Manual de investigação em ciências sociais. Lisboa: Gradiva, 1992.

Original recebido em: 10/07/2011

Aceito para publicação em: 10/07/2012

\section{Resumo sobre os autores}

Vanessa Nobre é uma aluna do Mestrado em Comunicação Multimídia da Universidade de Aveiro, atualmente alocada à investigação, design e desenvolvimento do serviço PNO.

ANIMUS R. Interamericana de Comunicação Midiática, http://www.ufsm.br/revistas E-ISSN 2175-4977, v. 11, n. 21, Jan-Jun(2012) 
Lídia Oliveira é doutorada em Ciências e Tecnologias da Comunicação (2002) pela Universidade de AveiroPortugal, onde é professora com agregação. Investigadora e Coordenadora Científica do CETAC.MEDIA - Centro de Estudos das Tecnologias e Ciências da Comunicação (http://www.cetacmedia.org/) dedica-se a investigar as implicações das tecnologias da informação e da comunicação em rede nas rotinas cognitivas e sociais dos indivíduos, dos grupos e das organizações, estando a sua investigação situada nos estudos de Cibercultura. 